\title{
Waste apple pomace conversion to acrylic acid: Economic and environmental assessment
}

\author{
Oseweuba Valentine Okoro ${ }^{1 *}$, Lei $\mathrm{Nie}^{2}$, Houman Alimoradi ${ }^{3}$ and Amin Shavandi ${ }^{*}$ \\ 1 BioMatter unit - École polytechnique de Bruxelles, Université Libre de Bruxelles (ULB), Avenue F.D. Roosevelt, 50 - \\ CP 165/61, 1050 Brussels, Belgium; oseweubaokoro@gmail.com or oseweuba.okoro@ulb.be (O.V.O) and amin.shavandi@ulb.be \\ (A.S.) \\ $2 \quad$ College of Life Sciences, Xinyang Normal University (XYNU), Xinyang 464000, China; nielei@xynu.edu.cn \\ 3 School of Biomedical Sciences, University of Otago, Dunedin, New Zealand; houman.alimoradi@otago.ac.nz (H.A.) \\ * Correspondence: oseweubaokoro@gmail.com or oseweuba.okoro@ulb.be (O.V.O) and amin.shavandi@ulb.be (A.S.)
}

\begin{abstract}
The global demand for acrylic acid (AA) is increasing due to its wide range of applications. Due to this growing demand, alternative AA production strategies must be explored to avoid the exacerbation of prevailing climate and global warming issues since current AA production strategies involve AA production using fossil resources. Investigations on alternative strategies for AA production therefore constitute an important research interest. The present study therefore assesses waste apple pomace (WAP) as a feedstock for the sustainable AA production. To undertake this assessment, process models, based on two production pathways were designed, modelled and simulated in ASPEN plus ${ }^{\circledR}$ software. The two competing production pathways investigated include a process incorporating WAP conversion to lactic acid (LA), prior to LA dehydration to generate AA (denoted as the FD pathway) and another process involving WAP conversion to propylene, prior to propylene oxidation to generate AA (denoted as the TFO pathway). Economic and environmental performances of the FD and TFO pathways were assessed via the minimum selling price (MSP) and potential environmental impacts per h (PEI/h) metrics. The study was able to show that the FD pathway presented an improved economic performance (MSP of AA: US $\$ 1.17$ per $\mathrm{kg}$ ) performance compared to the economic performance (MSP of AA: US $\$ 1.56$ per $\mathrm{kg}$ ) of the TFO pathway. Crucially, the TFO process was shown to present an improved environmental performance (2.07 $\mathrm{kPEI} / \mathrm{h})$ compared to the environmental performance of the FD process $(8.72 \mathrm{kPEI} / \mathrm{h})$. These observations suggests that the selection of the preferred AA production will require a trade-off between the performance measures, and the integration of a multi-criteria decision assessment in future work.
\end{abstract}

Keywords: acrylic acid; economic assessment; waste valorization; waste apple pomace; bio-refinery 


\section{Introduction}

The increasing threat of catastrophic climate effects [1] due to anthropogenic greenhouse gas (GHG) emissions and natural resource depletion have, in recent times, motivated research into the production of 'green' products. Some of these green products, produced via bio-refinery of biomass, are capable of partly (or completely) replacing their fossil fuel alternatives [2,3]. Bio-refinery technologies constitute sustainable progressions that incorporate biomass conversion technologies to facilitate the conversion of biomass to high-value products, and thus, promote the circular bio-economy paradigm [4]. Given that the implementation of such bio-refineries has thus far been limited by low profitability and poor commercialization concerns [3], the use of waste biomass streams was proposed as one strategy that may enhance overall economic performance given that feedstock cost constitutes an important factor that influences bio-refinery economic performance [3][4]. The present study therefore proposes the utilization of the waste biomass resources of waste apple pomace (WAP) as a useful bio-refinery feedstock. WAP constitutes an abundant biomass resource, with $\sim 18 \times 10^{9} \mathrm{~kg}$ of pomace estimated to be generated globally per year [5]. The poor management of this WAP stream may lead to unfavorable environmental outcomes such as uncontrolled GHG emissions from the disposal of pomace in landfills, unwanted acidification of agricultural soils via leachate formation and also the pollution of underground waters [6]. The utilization of WAP as a biomass resource therefore presents an opportunity for value extraction while also circumventing waste management concerns [7]. The current study therefore seeks to investigate the production of AA from WAP. Acrylic acid (AA; $\mathrm{CH}_{2}=\mathrm{CHCOOH}$ ) is the simplest of the unsaturated acids [8-10]. AA is an important product that is characterized by several significant end uses such as supper absorbent polymers, artificial leather and textiles (Figure 1). Figure 1 also shows that $42 \%$ of acrylic acid generated is employed in the manufacturing of dispersions i.e. detergents. In addition, AA may have other applications 'others' including in the production of acrylic-based polymers for fabricating corneal prosthesis, contact lenses, and in tissue engineering (these applications are shown as 'Other' in Figure 1) [11,12].

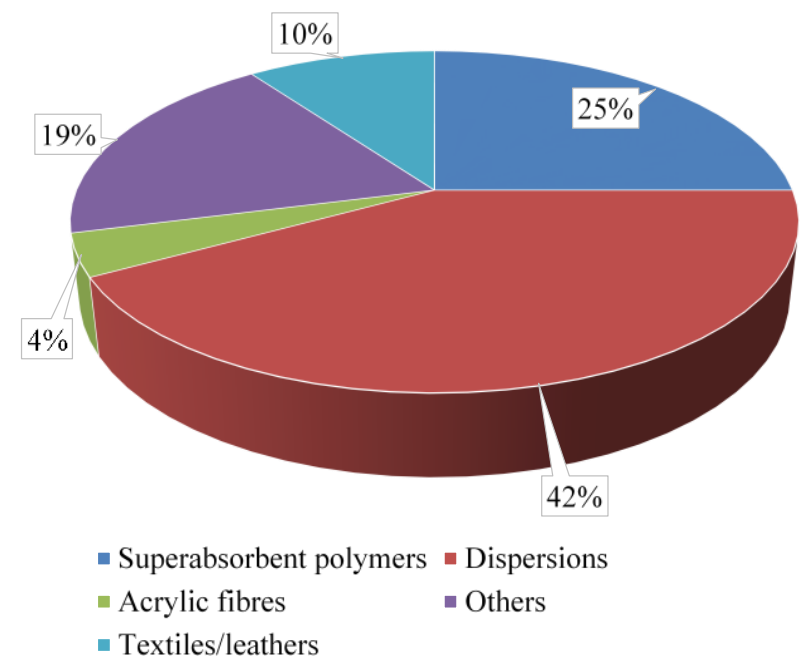

Figure 1: Acrylic Acid by End-Use [13].

The wide range of AA application is, partly due to its ability to achieve rapid polymerization and its efficiency in delivering carboxylate functionality in commercial products [14]. The importance of AA is demonstrated by the annual global market size and market demand, predicted to reach US $\$ 22.55$ billion and 8750 kton respectively by $2022[15,16]$. Currently, AA is commercially obtained via the catalytic oxidation of olefins [8-10] which are derived from the refining of fossil crude [8,9]. Such a commercial use of fossil crude exacerbates GHG emissions and natural resource depletion concerns. AA can also be produced from the non-fossil feedstocks of glycerol or biomass [17-24]. Notably, since 
glycerol typically requires additional production operations (i.e. as a by-product of the biodiesel production process), the use of freely available biomass as a feedstock may constitute a more sustainable strategy. The literature reveals that (non-fossil) AA may be produced from biomass, via stepwise processes, involving an initial LA acid production step (via sugar fermentation) followed by LA dehydration [25-27]. However, in the current study 'syngas pathway' that incorporates the conversions of biomass to $(\rightarrow$ ) propylene $\rightarrow$ AA (i.e. TFO pathway) has been suggested. We hypothesize that this pathway may be more favorable because unlike the biomass $\rightarrow$ LA $\rightarrow$ AA pathway that only utilizes polysaccharides present in biomass for $\mathrm{AA}$ production (i.e. via polysaccharide fermentation), all fractions of the biomass feedstock including the lignin fraction are employed in AA production in the proposed pathway via a preliminary syngas production step (i.e. thermochemical transformation). Therefore, to evaluate our hypothesis, in the present study we undertake an economic and environmental assessment of the two pathways that can transform WAP to AA (i.e. via the TFO and FD pathways). In spite of the importance of AA to our best of knowledge, no comparative economic assessment of AA production processes from WAP has been reported in the literature. Additionally, recognizing the importance of addressing environmental performance concerns, the current study also seeks to comparatively $\mathrm{ex}^{-}$ plore the environmental performances of the alternative AA production pathways. Since the feedstock collection and transportation to the AA production site is assumed to be similar for both pathways, only environmental impacts of the stand-alone AA production facilities will be assessed. Thus the assessment of impacts associated with environmental risk, waste minimization opportunities and raw materials [28-30] acquisition are beyond the scope of the present study and are not presented here. The comprehensive approach to the comparative study in the present work therefore emphasizes its novelty.

\section{Materials and Methods}

In this study, the commercial software ASPEN Plus ${ }^{\circledR}$ version 11 (Aspen Technology Inc., Cambridge, Massachusetts, USA) was used to design, model and simulate AA production via the TFO and FD pathways. Calculations, involving mass balance, energy balance, chemical and phase equilibrium were undertaken in ASPEN Plus ${ }^{\circledR}$. The WAP was modelled according to its reported chemical composition [31] ,proximate and elemental composition [32]. These data are presented in Tables S1 and S2 in the supplementary file A.

Modelling of other chemical inputs was achieved using the data library in ASPEN Plus. The nonrandom two-liquid (NRTL) thermodynamic property method is sufficient to model the properties (i.e. activities, fugacities, fugacity coefficients etc.) of chemical species in different phases and in complex systems [33-36]. We therefore, employed NRTL in the modeling process. In the present study, the reactors were modelled based on experimental results obtained from literature as discussed below (section 2.1), using the stoichiometric reactor models (RSTOIC). The RSTOIC reactors are based on the knowledge of fractional conversion of reacting species. For complex, reactions such as those involved in gasification processes, it was assumed that thermodynamic equilibrium is attained since the rates of associated chemical and physical-chemical reactions are infinitely high [37]. The gasification reaction was therefore modelled using the two equilibrium reactor models (RGIBBS) reactors in ASPEN Plus ${ }^{\circledR}$. In the RGIBBS model, ASPEN plus determines the concentration of species by minimizing the Gibbs free energy $\left(G_{\text {total }}\right)$ of the system which is defined as follows [38-40];

$$
G_{\text {total }}=\sum_{i=1}^{N} n_{i} G_{f . i}^{0}+\sum_{i=1}^{N}\left(n_{i} R T \ln \left(\frac{f_{i}}{f_{i}^{o}}\right)\right)
$$

where $f_{i}^{O}$ for gas phase species, is equal to 1 bar such that,

$$
f_{i}=\theta_{i} y_{i} P
$$

while for liquid phase species,

$$
\frac{f_{i}}{f_{i}^{o}}=a_{i}
$$


where $f_{i}, G_{f, i}^{0}$ and $\theta_{i}$ represent the standard molar fugacity, the Gibbs free energy of formation at 1 bar and the fugacity coefficient of the ith specie respectively. $T, R$ and $y_{i}$ represent the temperature in $\mathrm{K}$, the universal gas constant $(8.314 \mathrm{~J} / \mathrm{mol} \mathrm{K})$, the mole fraction vapour of the $t$ th specie respectively.

Furthermore, all pumps, turbines and compressors were modelled as isentropic units [41]. Finally, distillation processes were modelled using the RADFRAC model Aspen Plus ${ }^{\circledR}$, which facilitates rigorous energy and mass balance calculations and can be used to facilitate the separation of highly nonideal liquid mixtures [42]. To determine the column design specifications, the design parameters (i.e. number of stages, reboiler duty, reflux ratio etc.) were estimated using the Fenske-Underwood-Gilliland correlation model in Aspen Plus ${ }^{\circledR}[41,43]$.

\subsection{Process description}

Initially, the FD process that employs LA as a precursor to AA via its dehydration was investigated, according to the simplified process flow diagram presented in Figure 2 and is based on similar techniques which were used for LA production as described in [44]. Figure 2 shows that initially, the water content of the WAP is reduced to $50 \mathrm{wt. \%}$ from $67 \mathrm{wt. \%}$ (Materne company, Brussels Belgium) via mechanical dewatering operations. The dewatered WAP is then homogenized at $1 \mathrm{~atm}$ and at a temperature of $25^{\circ} \mathrm{C}$. The duties required for the dewatering and homogenisation operations are specified as $2 \mathrm{~kW}$ per $1 \mathrm{~m}^{3}$ of feed and $1.5 \mathrm{~kW}$ per ton of feed, respectively and are incorporated in the simulation using Fortran codes [45,46]. Pre-treatment of the WAP is subsequently undertaken, for lignin separation, via hot water treatment to minimize the generation of inhibitors (i.e furfural) that may limit the efficiency of the downstream fermentation operations $[6,47,48]$. This hot water treatment approach was also established to limit polysaccharide losses during biomass pre-treatment as discussed in the literature $[6,47,48]$. According to the well-established experimental approach employed in the literature [49], the hot water pre-treatment is undertaken at the temperature of 142.4 ${ }^{\circ} \mathrm{C}$ and pressure $1 \mathrm{~atm}$ with a $65 \%$ sugar (C6 and C5) recovery achieved according to the reaction equations presented in Table S3 in the supplementary file A. To enhance process efficiency and energy self-sufficiency, onsite steam generation is achieved using the lignin fraction as a solid fuel [41]. The lignin separated is employed as a fuel for heat and electricity generation via a combined heat and power (CHP) plant, in accordance with the Rankine cycle as described in the literature [6]. In the CHP plant, pressurization of water to $20 \mathrm{~atm}$ is initially achieved using a pump operating at 0.9 efficiency. The pressurised water is then heated using heat generated from the boiler via the combustion of the solid fuel (in this case lignin) to facilitate the production of superheated steam. Electrical energy is then generated via the expansion of the pressurised superheated steam to $1 \mathrm{~atm}$, in an isentropic turbine. The steam is then condensed and is made available for reuse within the system. Figure 2 then shows that the lignin-free stream (after hot water treatment) is subjected to a fermentation operation under the action of Lactobacillus casei sub sp. rhamnous (ATCC 10863) at $45^{\circ} \mathrm{C}$ and pressure of $1 \mathrm{~atm}$ [50]. This microbe is used in the present study due to its capability to metabolise C5 ( $\sim 80 \%$ conversion) and C6 ( 100 \% conversion) sugars to produce LA according to the reactions summarised in Table S3 (supplementary file A). At the conclusion of the fermentation process, the broth is subjected to precipitation treatment followed by acid treatment using $\mathrm{Ca}(\mathrm{OH})_{2}$ at the temperature of $95{ }^{\circ} \mathrm{C}$ to facilitate the production of $\mathrm{C}_{6} \mathrm{H}_{10} \mathrm{CaO}_{6}$ for its separation from the solution [51-53]. The $\mathrm{C}_{6} \mathrm{H}_{10} \mathrm{CaO}_{6}$ is then subjected to acid treatment to enable the recovery of LA, with the waste stream of gypsum generated. Stage-wise separation of the $\mathrm{C}_{6} \mathrm{H}_{10} \mathrm{CaO}_{6}$ and the gypsum is assumed to be sufficient and is achieved using filtration at $25^{\circ} \mathrm{C}$ and $1 \mathrm{~atm}$ [51-53]. Since the dehydration of the LA to AA requires that the LA stream has a LA content of $50 \mathrm{wt} . \%$ [54], a vaporization operation is imposed at the temperature of $100{ }^{\circ} \mathrm{C}$ to increase the concentration of LA and achieve $50 \mathrm{wt} . \%$ concentration [51-53]. In accordance with the work of Ghantani et al., [54] LA (50 wt.\% moisture) dehydration to produce AA is achieved under the action of $\mathrm{Ca} / \mathrm{P}(1.3$ molar ratio), with LA presenting a $100 \%$ conversion when subjected to a temperature condition of $375^{\circ} \mathrm{C}$. The dominant dehydration reaction facilitates the production of AA, water and a side decarboxylation reaction facilitates the production of $\mathrm{CO}$ and acetaldehyde $\left(\mathrm{C}_{2} \mathrm{H}_{4} \mathrm{O}\right)$, with the AA selectivity specified as 60\% [54]. The exit stream is then initially degassed for the recovery of $\mathrm{CO}$, which is utilized as a gaseous fuel in the CHP plant. The $\mathrm{CO}$ gas has a higher heating value (HHV) of $4.368 \mathrm{MJ} / \mathrm{kg}[55]$. Since it is not possible to separate AA from water via conventional distillation or rectification because of the formation of a minimum boiling azeotrope [56], an extractive distillation approach is employed [57]. Several organic solvents have been reported in the literature for AA 
extraction from an aqueous solution. These solvents include diisopropyl ether, isopropylacetate, methylisobutyl ketone and toluene [57]. Song et al., [57] however recommended toluene as the preferred solvent for the extraction when the combined effects of extraction capacity and solvent cost are considered. In the present simulation, toluene is therefore employed to facilitate AA extraction. In this approach the stream exiting the dehydration reactor is rapidly cooled to $25^{\circ} \mathrm{C}$ using a quencher to reduce the risk of polymerization of AA, after which the mixture is fed to a liquid-liquid extractor, with toluene as the solvent to facilitate the separation of aqueous components from AA [57]. The toluene-AA steam is then distilled to facilitate solvent recovery with associated AA generated as the bottom stream [56]. The recovered toluene is cooled and condensed and made available for further extractions. $\mathrm{Fi}^{-}$ nally, the aqueous stream is distilled to facilitate acetaldehyde recovery, as a by-product of the process. The alternative AA production process (simplified) is presented in Figure 3 which shows the TFO pathway. The gasification operation described in Figure 3 is based on generic processes previously described in the literature [58-60]. After the initial dewatering step, the WAP stream is then subjected to a drying operation. The dried WAP is then transferred to the reactor where the partial oxidation of the WAP is achieved under the action of steam (Figure 3). 


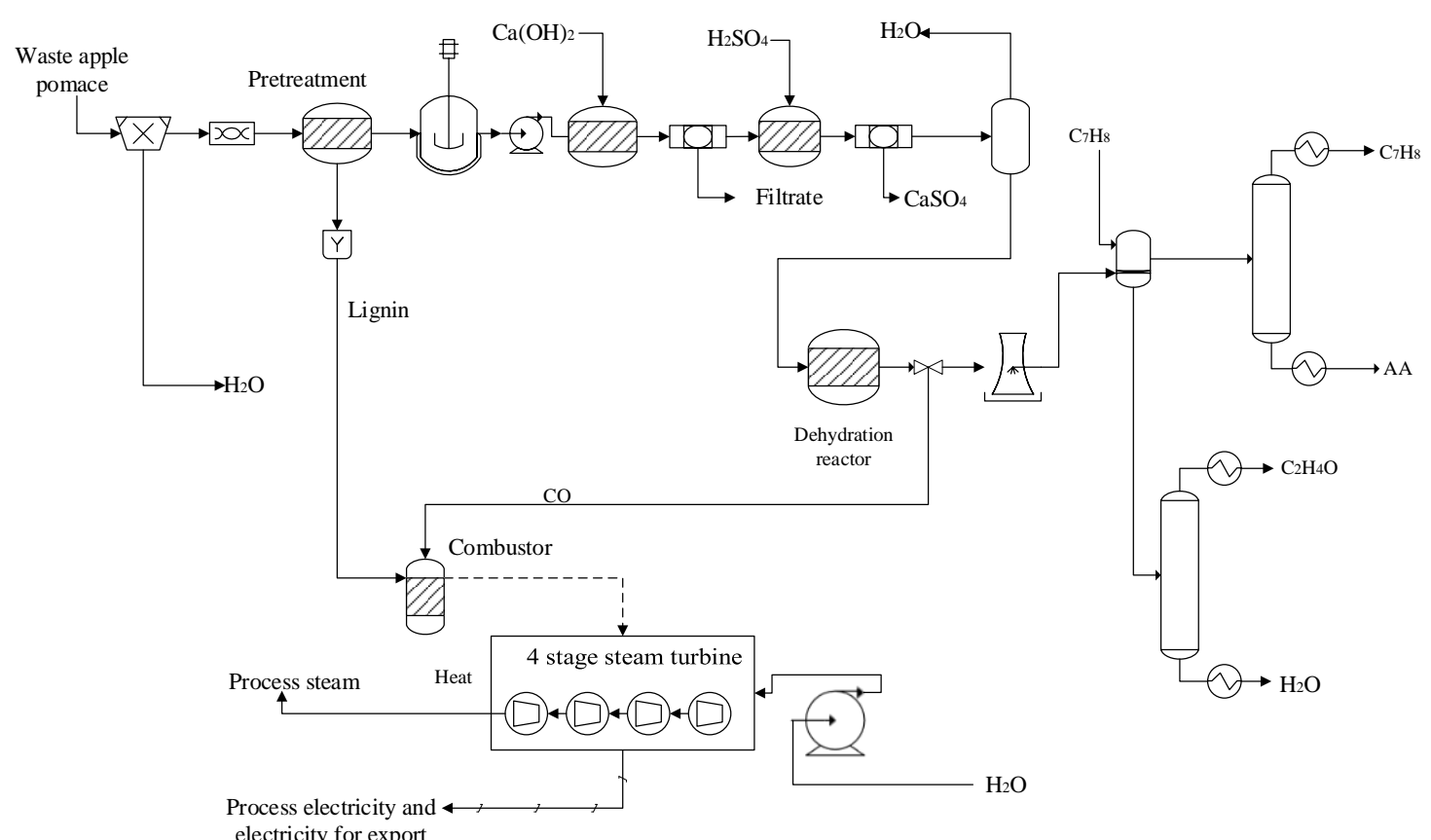

Figure 2: Simplified process flow diagram for acrylic acid production from waste apple pomace using the fermentation-dehydration (FD) pathway involving LA production as a precursor to AA production. 
Molecular sieves

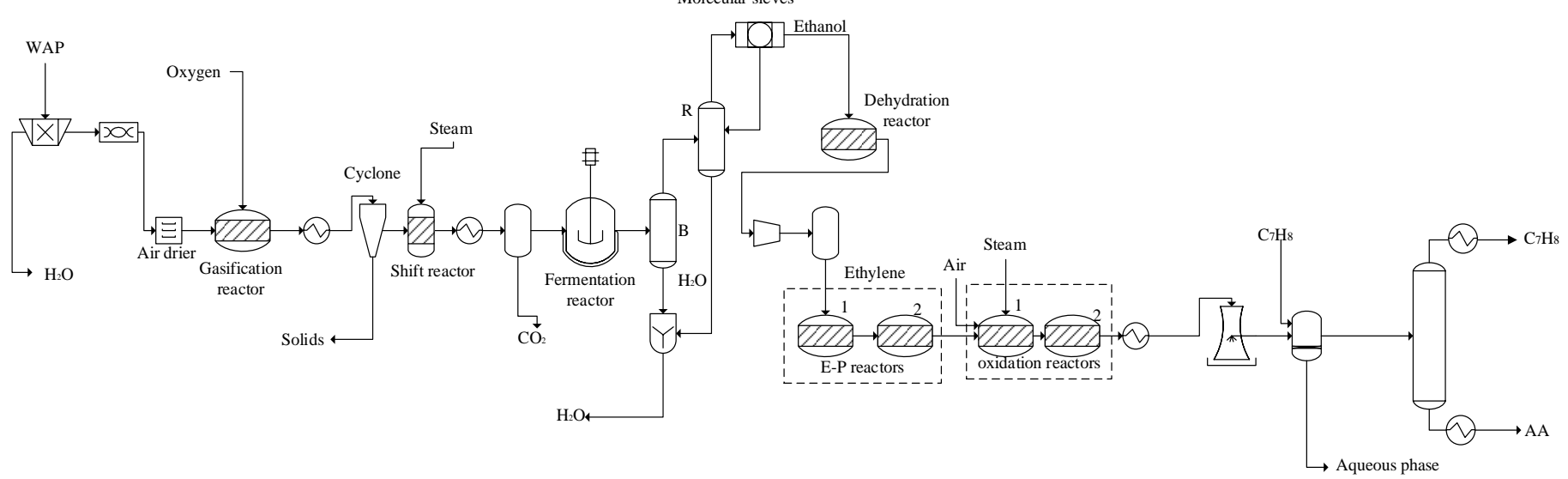

Figure 3: Simplified process flow diagram for acrylic acid production from waste apple pomace using the thermochemical-fermentation-oxidation pathway involving the propylene production as a precursor. 
The typical gasification reactions are summarised in Table S3. Herein, we used steam gasification as steam facilitates the production of syngas $\left(\mathrm{CO}\right.$ and $\left.\mathrm{H}_{2}\right)$ characterized by higher $\mathrm{H}_{2}$ and reduced $\mathrm{CO}_{2}$ contents $[60,61]$. To further decrease in the $\mathrm{CO}_{2}$ generation a steam-biomass ratio of 0.5 is imposed as detailed before [62]. The gasification operation is specified as being undertaken at the temperature of $1000{ }^{\circ} \mathrm{C}$ as the applying temperatures higher than $800^{\circ} \mathrm{C}$ minimizes tar formation in gasification sys ${ }^{-}$ tems [58]. Notably, at gasification temperatures ranging from $900{ }^{\circ} \mathrm{C}-1000{ }^{\circ} \mathrm{C}$, tar formation is significantly mitigated due to tar cracking [58,62]. This statement is consistent with other process models developed in the literature where tar formation was not considered [63,64]. Additionally such high temperatures reduce the risk of the production of heavy hydrocarbons (i.e $>\mathrm{C} 4$ ) in the gasification process [65]. At the conclusion of the gasification reaction, the exit stream is cooled to $37{ }^{\circ} \mathrm{C}$ and the solids (char) present in the stream, removed using a cyclone. The current study assumes that the char is composed of carbon and ash only [62]. The syngas product is then transferred to a fermenter, operating at the mesophilic temperature of $37{ }^{\circ} \mathrm{C}$ and pressure of $1 \mathrm{~atm}$. Fermentation of the syngas is achieved under the action of acetogenic microorganisms such as Clostridium ljungdahlii and Clostridium carboxidivorans [66,67] according to equations presented in Table $\mathrm{S} 3$. $\mathrm{CO}$ and $\mathrm{H}_{2}$ conversions to ethanol are specified as $90 \%$ and $70 \%$ respectively, as previously reported by Phillips et al., [68]. According to Klasson et al.'s work, [68], the aforementioned conversions are achieved when fermentation of syngas occurs in the presence of $\sim 0.8 \mathrm{~g}$ of Clostridium ljungdahlii per litre of fermentation broth. Having concluded the fermentation operation, the fermentation broth containing the ethanol is purified via a stage-wise distillation process as described in the literature [69]. Briefly, the fermentation broth is transferred to a 'beer' column (B) where stripping of ethanol from the stream is achieved with the resulting vapour phlegm composed of $\sim 35$ wt.\% of ethanol and 65 wt.\% of water. Further concentration of the vapour phlegm is achieved when the stream is transferred to the rectification column (R) such that a distillate containing 91 wt.\% of ethanol is produced. To facilitate further concentration of the ethanol containing stream, the distillate is dehydrated using molecular sieves, to achieve an ethanol product with a purity of $\sim 99 \mathrm{wt} . \%$. Having generated the ethanol product, the stream is transferred to the dehydration reactor where dehydration is achieved at $350{ }^{\circ} \mathrm{C}$ and $1 \mathrm{~atm}$ for ethylene production in accordance with the work of Arvidsson and Lundin [70] (reactions in Table S3). In accordance to literature the conversion of ethanol to ethylene is specified as $99.9 \%$ while the side reaction involves the conversion of the residual ethanol to diethyl ether [69,70]. Given that acetic acid is produced as a by-product of the syngas fermentation process and unreacted ethanol is retained in the stream after the dehydration reaction, it is assumed that the acetic acid and ethanol are available to undergo esterification reaction for ethyl acetate production. Both streams are therefore transferred to an esterification reactor (reaction in Table S3) operating at $80{ }^{\circ} \mathrm{C}$ and 1 atm with a reaction conversion of $84 \%$ achieved (ethanol as the limiting reactant) [71].

Cleaning of the ethylene product is achieved using activated carbon. To produce propylene from ethylene, the methods highlighted in the novel and recent study by Beucher et al., [72] are employed. To this regard, the ethylene product is subjected to a cascade of reactions involving two reactors for propylene formation. In the first reactor, ethylene is converted ( $\sim 85 \mathrm{wt} . \%$ conversion) to 2 -butene under the action of a Nickel based catalyst at temperature and pressure conditions of $120{ }^{\circ} \mathrm{C}$ and $29.6 \mathrm{~atm}$ respectively. The exit stream is then transferred to the second reactor, where the 2 -butene in the stream reacts with the previously unconverted ethylene at temperature and pressure conditions of 450 ${ }^{\circ} \mathrm{C}$ and 1 tam respectively to produce propylene, under the action of Tungsten oxide based catalyst. To produce AA from propylene, a well-established method were used [73]. According to Sanchez et al., [73], the stream containing the propylene is fed to a reactor together with air compressed at the pressure of $5.95 \mathrm{~atm}$ and low pressure steam at the pressure and temperature of $5.95 \mathrm{~atm}$ and $159{ }^{\circ} \mathrm{C}$ respectively. The propylene, air and steam feed fractions are maintained at 1/7.75/3.75 (mass basis) [73]. In the first reactor, the propylene is then oxidized to facilitate its initial conversion to acrolein, $\mathrm{AA}$, acetic acid and $\mathrm{CO}_{2}$ with conversions of $79 \%, 6 \%, 12 \%$ and $3 \%$ respectively achieved, under the action of Bismuth molybdate catalyst at the temperature of $350{ }^{\circ} \mathrm{C}$ [73]. The initial oxidation of propylene reactions in reactor 1 are presented in the Table S3. Figure 3 subsequently shows that the hot gaseous mixture, containing mostly acrolein, is transferred to the next reactor 2, where acrolein conversion to $\mathrm{AA}$ is achieved under the action of vanadium-molybdenum oxide, at the temperature of 300 ${ }^{\circ} \mathrm{C}$. An AA production yield of $85 \%$, is attained in reactor 2 [73]. The gaseous product is then cooled 
from $300{ }^{\circ} \mathrm{C}$ to $25{ }^{\circ} \mathrm{C}$ with the the liquid-liquid extraction module discussed in FD pathway above executed to facilitate AA recovery. In the TFO pathway, the heat from all exothermic reactor units in the bio-refinery (i.e. propylene oxidation reactors [74]), is recovered in form of high pressure steam at $20 \mathrm{~atm}$ and employed in electricity generation (via the CHP). The specifications of major operations discussed above are presented in Table S3 in the supplementary file A. Having designed and modelled the AA production processes, energy balance calculations were undertaken, using the ASPEN energy analyser ${ }^{\circledR}$ V.11 $[69,75]$.

\subsection{Economic assessments}

Plant availability was assumed to be $7200 \mathrm{~h}$ per year. To assess the economic performances of the AA productions processes, the minimum selling prices (MSPs) of the AA product generated from both processes were determined. The MSP was specified as the price of AA for which the net present value (NPV) of the project was equal to zero, with the NPV determined using a discounted flow table and calculated as follows [60];

$$
\mathrm{NPV}=-\mathrm{TCI}+\sum_{n=1}^{t} \frac{N_{R}}{(1+i)^{n}}+\frac{S_{n}}{(1+i)^{n}}
$$

where TCI, $i$ and $n$ denotes the total capital investment cost in US $\$$, discount rate (10\%), and project lifespan (30 y) respectively. $S_{\mathrm{n}}$ denotes the salvage value specified as zero, with straight-line depreciation assumed. $N_{R}$ denotes the net cash flow (annual cash flow less the assets) in US\$.

The total operating costs (TOC) of the FD and TFO processes were also determined as a summation of the fixed production cost components (i.e costs incurred irrespective of the plant productivity), and the variable production costs (i.e. cost proportional to the plant outputs) [60]. The costing relations employed in estimating these cost components are presented in supplementary file A. The TCI was determined from equipment purchase costs provided by the ASPEN process economic analyzer V11 (APEA). These purchase costs were determined based on mapping algorithms that employ the mass and energy balance simulation results for equipment sizing calculations. Based on the equipment purchase costs, the TCI costing approach is summarized in Figure 4 [76].

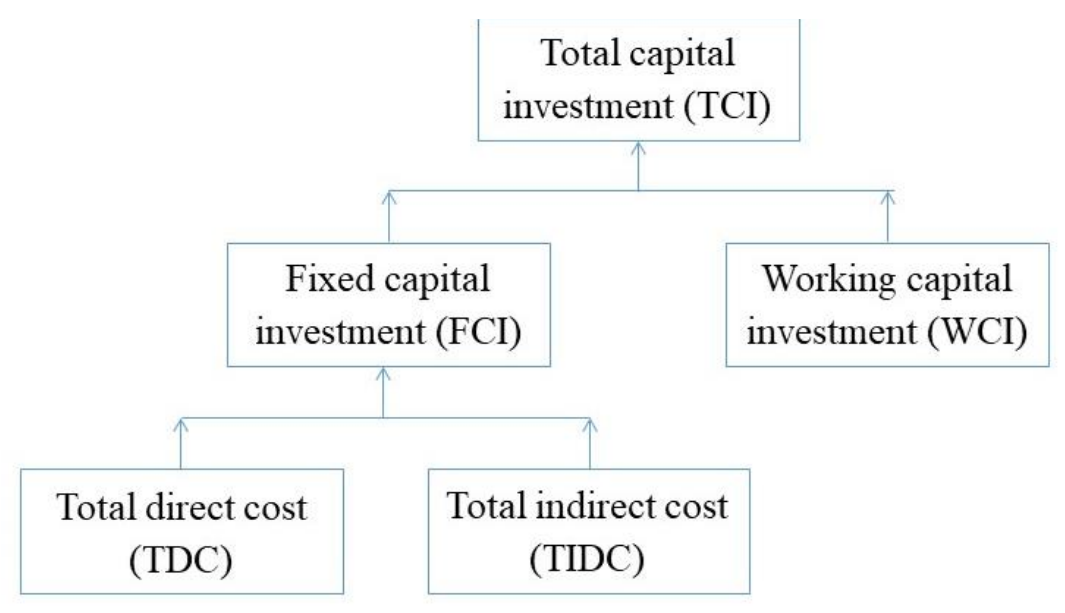

Figure 4: Total capital investment cost components [76]

The full description of each of the cost components are beyond the scope of the current study and may be found elsewhere [77]. The associated TCI cost correlations are presented in the supplementary file A. In the present study the purchase cost of general equipment i.e distillation columns, heater, cooler, tanks and pumps were obtained from APEA. In line with previous studies [78-80], the cost of specialized equipment such as the gasification reactor, cyclone, reactors and molecular sieves were obtained from literature and commercial vendors $[81,82]$ and the purchase costs of these specialized equipment 
summarized in the supplementary file A. To account for inflationary effects from equipment purchase costs obtained in different years, Chemical Engineering Plant Cost Index (CEPCI) values were employed according to standard methods [60], with the CEPCI for the year of 2020 specified as 607.5[6] was employed. The purchase cost $p_{i}$ of these specialized, ith equipment, in US $\$$ was subsequently adjusted for the desired characteristic factor as follows [60,83];

$$
p_{i}=p_{i, F_{\text {ref }}}\left(\frac{F}{F_{\text {ref }}}\right)^{0.65}
$$

where $F$ and $F_{r e f}$ denote the characteristic factors such as the volume of the equipment in the present study and reference volume of the equipment; $p_{i, \text { ref }}$ denotes the purchase cost for the equipment with the reference characteristic factor and 0.65[84] denotes the scaling factor employed in the present study.

The economic assessment technique described thus far is the study estimate type (i.e. class 4 estimate) and is typically employed in facilitating conceptual studies [85]. The economic assessment technique was therefore specified as sufficient for the current comparative investigation. Finally, a summary of the economic assumptions employed in the present study are shown in Table 1.

Table 1: Economic parameters and assumptions

\begin{tabular}{cc}
\hline Parameter & Value \\
\hline Base year & 2020 \\
Project lifetime (y) & 30 \\
Plant availability (h/y) & 7200 \\
Tax rate (\%) & 30 \\
Discount rate (\%) & 10 \\
Salvage value (US $\$$ ) & 0 \\
Depreciation & Straight line \\
\hline
\end{tabular}

\subsection{Environmental performance assessment}

Since the current study is interested in the comparative assessment of the stand-alone alternative AA production pathways, the potential environmental impact (PEI) of the alternative processes were investigated was selected as a sufficient metric in this regard [86,87]. The PEI was measured using the WAR algorithm since it constitutes a powerful tool that facilitates rapid assessments of environmental impacts during the design stages of manufacturing processes $[87,88]$. PEI employs energy and mass balance results of the simulated process as inputs for the calculation of its constituent impact categories [69] highlighted in Table 2. The PEI out of a process is calculated as follows [89];

$$
\begin{aligned}
& \dot{I}_{\text {out }}{ }^{c p}=\sum_{i}^{c p} \dot{I}_{i}{ }^{\text {out }}=\sum_{i}^{c p} \dot{M}_{i}{ }^{\text {out }} \sum_{k} x_{i} \phi_{k} \\
& \dot{I}_{\text {out }}{ }^{e p}=\sum_{i}^{e p-g} \dot{M}_{i}{ }^{\text {out }} \sum_{k} x_{k i} \phi_{k}
\end{aligned}
$$

where $\dot{I}_{\text {out }}^{c p}$ denotes the rate of PEI out of the process from chemical interactions; $\dot{I}_{\text {out }}^{e p}$ denotes the rate of PEI out of a system from energy generation processes; $\dot{M}_{i}^{\text {out }}$ is the mass flow rate of exit streams from the process $i . \quad x_{k i}$ is the mass fraction of component $k$ in the exit stream $i$ and $\varnothing_{k}$ is the potential environmental impact due to component $k$. The parameter, $\varnothing_{k}$, denotes the sum of the specific PEI due to disposal of component $k$ to the environment leading to different impact categories $l$ as follows [89];

$$
\psi_{k}=\sum_{l} \alpha_{i} \phi_{k l}^{s}
$$


where, $\alpha_{i}$ denotes the relative weighting factor of impact categories, $l$ (Table 2 ), with all impact categories considered equally significant in the present study. In the present study the environmental impact of the processes were reported in terms of the PEI per unit mass of product stream. For simplicity, PEI/h from the biomass (WAP) have been considered negligible. Further descriptions of the WAR algorithm and the governing Equations are outside the scope of the present study and are presented elsewhere $[87,89,90]$. $[87,90]$

Table 2: Impact categories that constitute the basis of the potential environmental impact

\begin{tabular}{ccc}
\hline General Impact Category & Impact Category & $\begin{array}{c}\text { Measure of Impact Cate- } \\
\text { gory }\end{array}$ \\
\hline Human toxicity & Ingestion (HTPI) & LD50 \\
& Inhalation/dermal (HTPE) & OSHA PEL \\
Ecological toxicity & Aquatic toxicity (ATP) & Fathead Minnow LC50 \\
& Terrestrial toxicity (TTP) & LD50 \\
Global atmospheric impacts & Global warming potential (GWP) & GWP \\
Regional atmospheric im- & Ozone depletion potential (ODP) & ODP \\
pacts & Acidification Potential (AP) & AP \\
& Photochemical oxidation potential & PCOP \\
\hline
\end{tabular}

\section{Results}

Based on the processes described in section 2, the ASPEN plus developed models are presented in Figures 5 and 6, with the mass balance results of major streams presented in Table 3. Figure 5 rep- $^{-}$ resents the FD process which integrates WAP handling and homogenization, with pre-treatment (for sugar release), fermentation (for LA production) and dehydration (for AA production). The model developed based on TFO process is shown in Figure 6 and this includes WAP handling and gasification (for syngas production), syngas fermentation (for ethanol production), ethanol purification, ethanol dehydration (for ethylene production), ethylene to propylene conversions and propylene oxidation (for AA production) operations. The result in Table 3 shows that the FD process will facilitate the production of $1.94 \mathrm{tons} / \mathrm{h}(14 \mathrm{ktons} / \mathrm{y})$ of AA (97 wt.\% purity) and $0.34 \mathrm{tons} / \mathrm{h}(2.45 \mathrm{ktons} / \mathrm{y})$ of acetaldehyde as by-product. It is estimated that for the equal mass of feedstock, the resulting mass of AA generated via the FD process is approximately 6 times ( 1.94 tons $/ \mathrm{h}, 97 \mathrm{wt}$. \% purity) than that the TFO process (0.313 tons/h, 97 wt. \% purity). A by-product of $\mathrm{AC}$ of 1.2 tons/h was also generated 


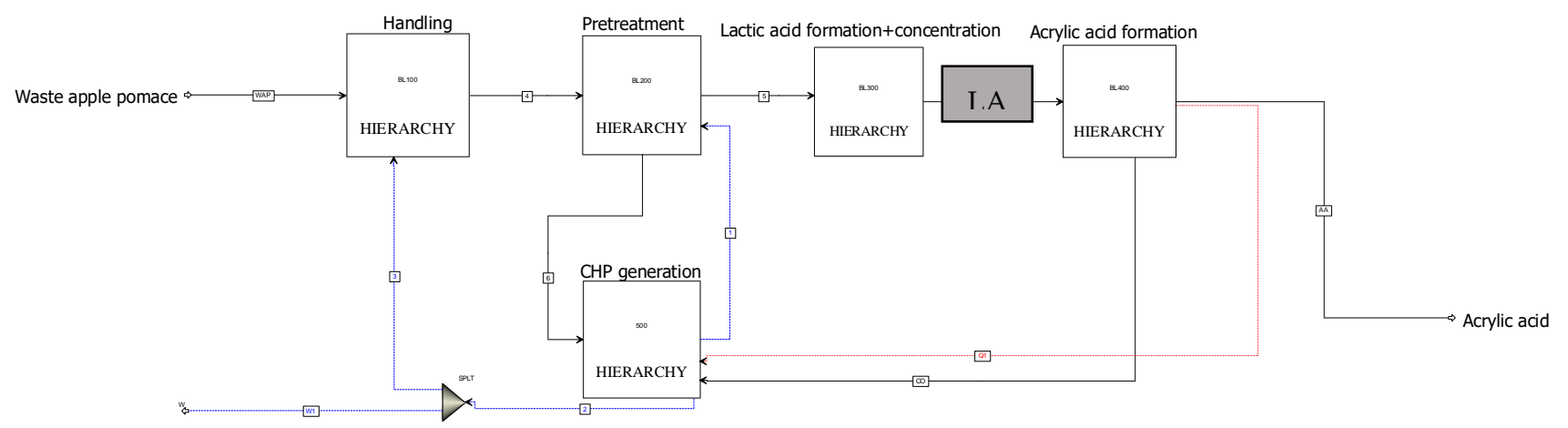

Figure 5: ASPEN plus output for AA production from WAP via the fermentation dehydration (FD) pathway (black continuous lines, red dash lines and blue dashed line denote material, heat and work flows).

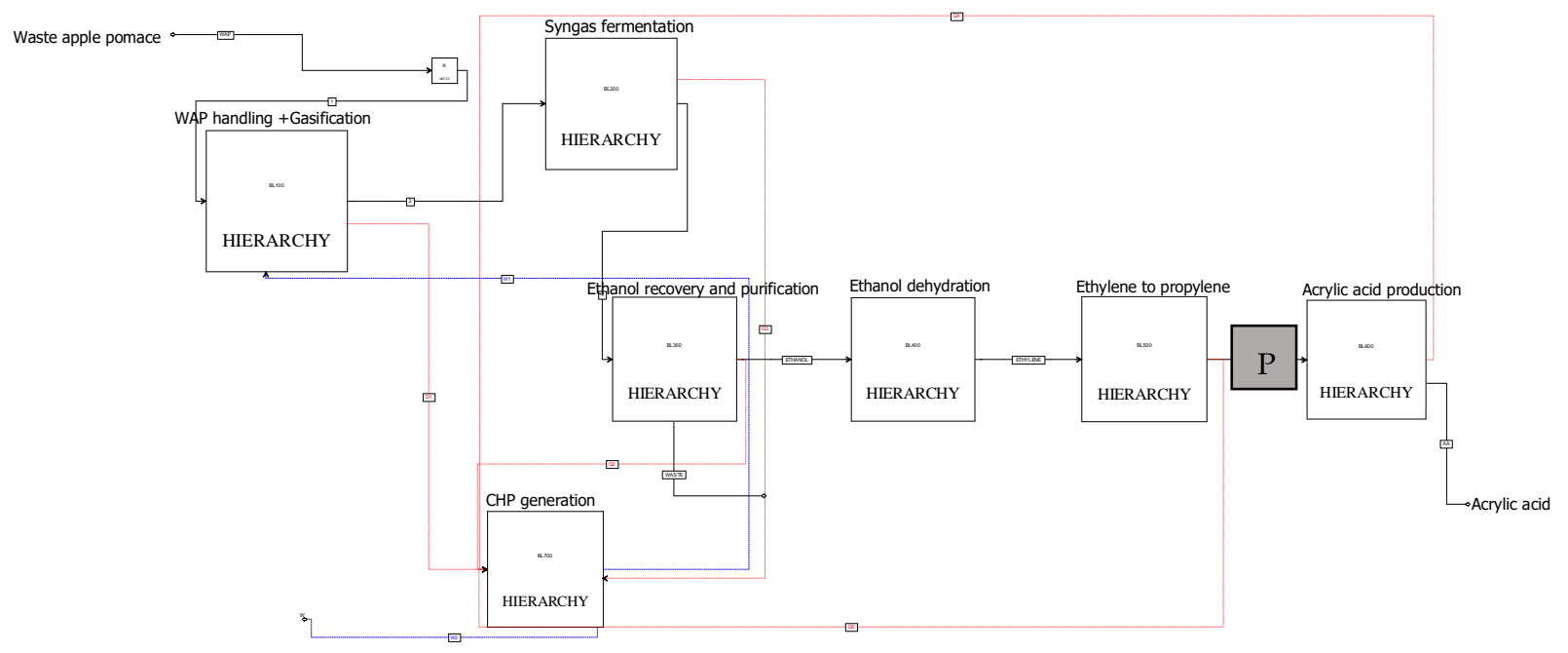

Figure 6: ASPEN plus output for AA production from WAP via the thermochemical-fermentation-oxidation (TFO) pathway (black continuous lines, red dash lines and blue dashed line denote material, heat and work flows). 


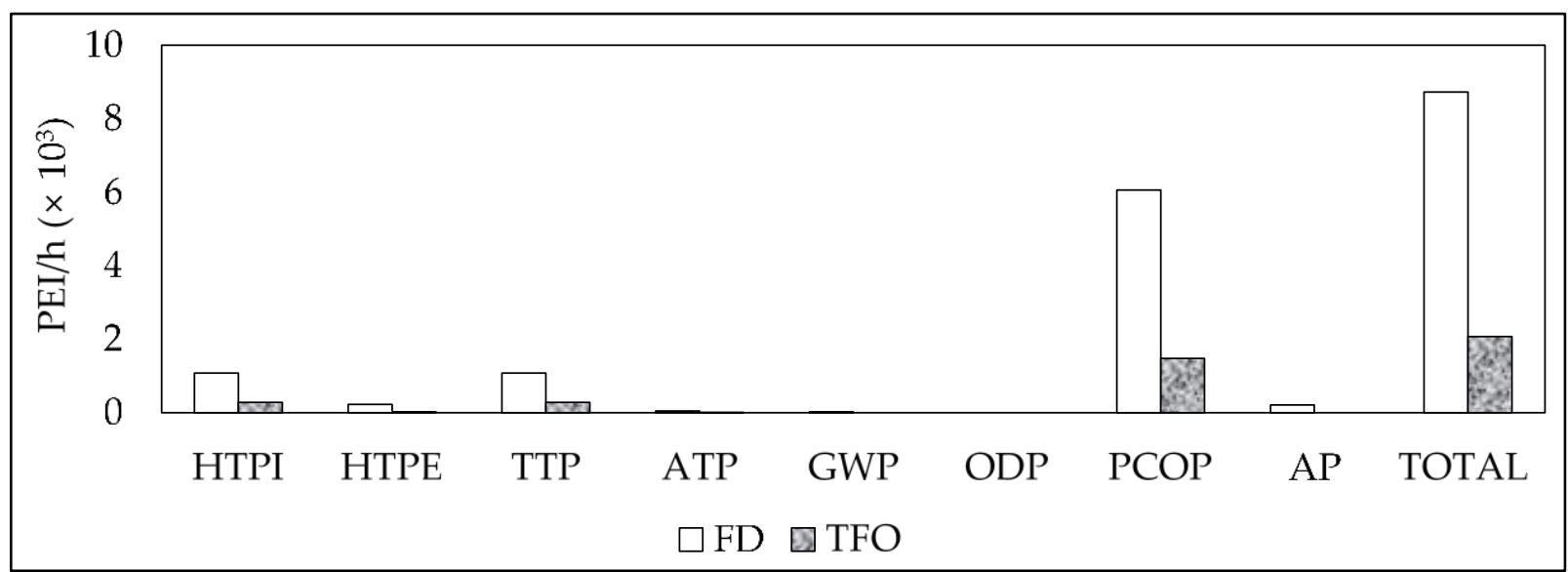

Figure 7: Potential environmental impacts per $\mathrm{kg}$ of product (PEI/kg) for the fermentation dehydration (FD) and thermochemical fermentation oxidation (TFO) pathways

Table 3: Mass balance results for major streams in the AA production processes

\begin{tabular}{ccccccccc}
\hline & \multicolumn{2}{c}{ Fermentation dehydration (FD) } & process & \multicolumn{2}{c}{ Thermochemical-fermentation-oxidation (TFO) process } \\
\cline { 2 - 7 } Stream name & Hydrolysate & Stream LA & AA & AC & Syngas & Ethyl acetate & Stream P & AA \\
\hline Mass Fractions $(x)$ & 0 & 0 & 0 & 0 & 0 & 0 & 0.550 \\
2-Butene & 0 & 0 & 0 & 0.980 & 0 & 0 & 0 \\
AC & 0 & 0 & 0.970 & 0 & 0 & 0 & 0 \\
AA & 0 & 0 & 0 & 0 & 0.610 & 0 & 0 & 0 \\
Carbon dioxide & 0 & 0 & 0 & 0 & 0.310 & 0 & 0 \\
Carbon monoxide & 0 & 0 & 0 & 0 & 0 & 0 & 0 \\
Ethanol & 0.018 & 0 & 0 & 0 & 0 & 0 & 0 \\
Fructose & 0.024 & 0 & 0 & 0 & 0 & 0 & 0 \\
Glucose & 0 & 0 & 0 & 0 & 0.080 & 0 & 0 \\
Hydrogen & 0 & 0.500 & 0 & 0 & 0 & 0 & 0 \\
LA & & 0.90 & 0 & 0 \\
\end{tabular}




\begin{tabular}{|c|c|c|c|c|c|c|c|c|}
\hline Methane & 0 & 0 & 0 & 0 & 0 & 0 & 0 & 0 \\
\hline Propylene & 0 & 0 & 0 & 0 & 0 & 0 & 0.450 & 0 \\
\hline Toluene & 0 & 0 & 0.030 & 0 & 0 & 0 & 0 & 0.030 \\
\hline Ethyl acetate & 0 & 0 & 0 & 0 & 0 & 1 & 0 & 0 \\
\hline Water & 0.955 & 0.500 & 0 & 0.020 & 0 & 0 & 0 & 0 \\
\hline Xylose & 0.006 & 0 & 0 & 0 & 0 & 0 & 0 & 0 \\
\hline Mass Flows (tons/h) & 99.30 & 7.83 & 1.94 & 0.33 & 0.483 & 1.166 & 0.478 & 0.313 \\
\hline
\end{tabular}

LA and P denote the streams containing crucial intermediate compounds of Lactic acid and propylene respectively. AC denotes Acetaldehyde

Table 4: External utility requirements of the conversion processes, assuming full heat integration.

\begin{tabular}{ccc}
\hline Process result & (FD) process & (TFO) process \\
\hline Externally required heating utility (MW) & 59.66 & - \\
Externally required cooling utility (MW) & 27.48 & 15.87 \\
Net electricity generated (MW) & 11.45 & 0.83 \\
\hline
\end{tabular}

FD denotes the Fermentation dehydration process and TFO denotes the Thermochemical-fermen-

tation-oxidation process

Table 5: Cost distribution for total capital investment for acrylic acid production via two pathways

\begin{tabular}{|c|c|c|}
\hline Costing components & Fermentation-dehydration pathway (FD) & Thermochemical-fermentation-oxidation (TFO) \\
\hline Warehouse cost $\quad$ (US $\$$ ) & 342807.9 & 536738.2 \\
\hline Equipment installation cost (US \$) & 771317.8 & 1207661.0 \\
\hline Home office and construction fee (US \$) & 385658.9 & 603830.5 \\
\hline Site development (US \$) & 8570198.2 & 13418455.1 \\
\hline Prorateable expenses (US $\$$ ) & 1006998.3 & 1576668.5 \\
\hline Project contingency $\quad(\mathrm{US} \$)$ & 1006998.3 & 1576668.5 \\
\hline Additional piping (US $\$$ ) & 2013996.6 & 3153337.0 \\
\hline Field expenses (US $\$$ ) & 1006998.3 & 1576668.5 \\
\hline Other costs (start up, permits etc) (US $\$$ ) & 1006998.3 & 1576668.5 \\
\hline Working capital $\quad$ (US \$) & 805598.6 & 1261334.8 \\
\hline Total capital investment (US \$) & 16917571.2 & 26488030.6 \\
\hline
\end{tabular}


Table 6: Cost distribution for total operating cost for acrylic acid production via two pathways

\begin{tabular}{ccc}
\hline Costing components & Fermentation-dehydration pathway (FD) & Thermochemical-fermentation-oxidation (TFO) \\
\hline Labour cost (US \$) & 1504296 & 1504296 \\
Maintenance cost (US \$) & 1353866.4 & 1353866.4 \\
Labour burden (US \$) & 113616.9 & 214100 \\
Property insurance (US \$) & 1127838.1 & 1765868.7 \\
Total variable cost (US \$) & 14834442.6 & 8791658.6 \\
Total operating cost (US \$) & 18934059.9 & 13629789.7 \\
\hline
\end{tabular}


Table 7: The minimum selling price (MSP) of acrylic acid

\begin{tabular}{cc}
\hline Process & MSP (US $\$ / \mathrm{kg}$ ) \\
\hline Fermentation-dehydration pathway (FD) & 1.17 \\
Thermochemical-fermentation-oxidation (TFO) & 1.56 \\
\hline
\end{tabular}

Employing ASPEN energy analyzer ${ }^{\circledR}$ V.11 discussed above in section 2.1, the externally required heating and cooling utilities required are highlighted in Table 4. Employing methods discussed in section 2.3, the economic performances of FD and TFO processes were assessed. The TCI and the total operating cost (TOC) components results are presented in Tables 5 and 6 respectively. Employing the TOC and TCI values, the economic performance parameters were determined and summarized in Table 7. Employing the WAR software and using the methods discussed earlier above in section 2.3 above, the PEI/kg for both processes are summarized in Figure 7

\section{Discussions}

Table 3 shows that based on the AA purity of 97 wt. \% achieved in the present study, the AA product can be designated as technical grade (i.e $94 \mathrm{wt} . \% \leq$ AA purity < $99.5 \mathrm{wt} . \%$ ) [91,92]. Such technical grade AA can be readily used in the synthesis of acrylate esters that can be transformed into co-monomers [93]. These co-monomers can be polymerized to produce valuable products such as surface coatings, adhesives, textiles, paints, polymeric materials etc.[93]. Table 3 also shows that the composition of syngas generated on a mass basis is $8 \%, 31 \%$, and $61 \%$ for $\mathrm{H}_{2}$, $\mathrm{CO}$, and $\mathrm{CO}_{2}$, which translates to mole basis equivalents of $62 \%, 17 \%$ and $21 \%$ respectively. This mole basis yields of $\mathrm{H}_{2}, \mathrm{CO}$, and $\mathrm{CO}_{2}$ is comparable to the experimentally determined mole composition of syngas of $\sim 60 \%$, $\sim 22 \%$ and $\sim 18 \%$ reported in the literature [94]. The mass balance results for major streams in the AA production processes are summarized in Table 3 . The table shows that only 0.478 tons/h of propylene is generated from 0.786 tons/h of ethanol, translating to a yield of $27 \mathrm{wt} . \%$. This observation is consistent with experimentally reported yield of propylene from ethanol, which was shown to range from $24.5-28.6 \mathrm{wt} . \%$ [95]. In addition, considering the mass flow rate of sugars $(\mathrm{C} 6+\mathrm{C} 5)$ in the hydrolysate $(4.77 \mathrm{ton} / \mathrm{h})$ and the mass flow rate of LA (i.e. 3.915 ton/h) presented in Table 3, the LA yield per unit mass of sugars can be calculated to be $82.1 \mathrm{wt} . \%$. This yield is consistent with the yield of LA of $88 \mathrm{~kg}$ of LA per $100 \mathrm{~kg}$ sugars (from apple pomace) and based on experimental work [96]. As expected, in both cases, the actual yield of LA is less than the theoretical yield of $1 \mathrm{~kg}$ of lactic per $1 \mathrm{~kg}$ of sugar [96]. Table 4 shows that while the external heating utility requirement of the FD pathway for AA production is 59.66 MW the external heating utility requirement of the TFO pathway is determined to be negligible. These results are based on the assumption that full heat integration is achieved. This observation is expected and consistent with processes that incorporate exothermic processes [97-99]. In the TFO process, the oxidation of propylene for the generation of acrolein, $\mathrm{AA}$, acetic acid and $\mathrm{CO}_{2}$ as discussed in section 2.1 is highly exothermic [74]. For such exothermic systems, the need for addition external heating utility is redundant. Similarly, since the exit hot streams (from the exothermic processes) are cooled by being employed as heat sources for steam generation the externally required cooling duty calculated (15.87 MW) is shown to be lower than the externally required cooling duty required in the FD process $(27.48 \mathrm{MW})$. Table 4 also shows that the FD process has the potential for higher net electricity generation potential of $11.45 \mathrm{MW}$, compared to the TFO process with the net electricity production potential of $0.83 \mathrm{MW}$. This observation is expected since in FD, the lignin fraction (HHV $=\sim 25.5 \mathrm{MJ} / \mathrm{kg}$ [100]), employed as a solid fuel in the boiler for steam generation has a higher energy density compared to the TFO process where $\mathrm{CO}(\mathrm{HHV}=4.368 \mathrm{MJ} / \mathrm{kg}[55])$ is employed as the gaseous fuel. Clearly, the combustion of the lignin will lead to the generation of more boiler heat leading to more energetic steam generation, compared to the combustion of CO. Table 5 shows that the total capital investment (TCI) calculated for the TFO process of US\$ 26.5 million is $56 \%$ more $(\sim)$ than the value calculated for the FD process of US\$16.9 million. This observation could be justified by the differences in processing complexity, with the TFO process clearly shown to incorporate more processing steps than the FD process. A higher number of processing steps employed typically translates to a higher capital cost. This statement is consistent with the fundamental basis of the 'functional unit' approach in capital cost estimation [101,102]. Table 5 also shows that in both FD and TFO processes, the equipment installation cost is the most crucial costing component and constitutes $51 \%$ of the total TCI. This observation is constituent with the class 4 estimation approach that considers the major equipment cost as the most crucial in calculating initial project cost estimates. Table 6 on the other hand, shows that, the total operating cost of the FD process (US\$ 18.9 million) exceeds the total operating cost of the TFO process (US\$13.6 million) with the variable cost component accounting for $78 \%$ and $65 \%$ respectively. This observation is expected since based on model descriptions in section 2.1, the FD process will involve a higher variable cost (i.e. chemical inputs of $\mathrm{Ca}(\mathrm{OH})_{2}, \mathrm{H}_{2} \mathrm{SO}_{4}$, catalyst, toluene required and waste gypsum management cost) compared to the TFO process (catalyst, toluene). Table 7 shows that the MSPs of the AA produced via the TFO and FD processes are US $\$ 1.56$ per $\mathrm{kg}$ and US\$1.17 per $\mathrm{kg}$ respectively. This observation is due to the generation of more AA product in FD process, as discussed above and also the lower TCI requirement of the FD process as discussed above. 
Figure 7 shows that the FD pathway has a higher environmental impact ( $8.72 \mathrm{kPEI} / \mathrm{h}$ ) compared to the TFO pathway $(2.07 \mathrm{kPEI} / \mathrm{h})$. In both pathways the photochemical oxidation potential (PCOP) index constitutes the highest impact category with values of $6.06 \mathrm{kPEI} / \mathrm{h}$ and $1.48 \mathrm{kPEI} / \mathrm{h}$ for the FD and TFO pathways respectively. This observation may be due to the larger mass of toluene required in the FD process $(642.2 \mathrm{~kg} / \mathrm{h})$ for AA recovery compared the TFO process $(102.7 \mathrm{~kg} / \mathrm{h})$ and employed in AA recovery. Volatile organic compounds such as toluene have the potential of undergoing photochemical reactions with oxides such as nitrous oxides $\left(\mathrm{NO}_{\mathrm{x}}\right)$, leading to unwanted smog formation, implying that higher masses of toluene will exacerbate the PCOP pollution risk [87]. Figure 7 also shows that for the impact categories of HTPI, HTPE and TTP, the impacts associated with the FD process exceed the TFO process. These observations may be a consequence of the higher mass of toluene employed in FD compared to the TFO process. Notably the wastewater stream generated via the FD process is characterized by residual sulphuric acid and calcium sulfate which are consequences of the lactic acid purification process discussed in 2.1 above. Sulphuric acid and calcium sulfate have a potential of exacerbating unfavorable environmental impacts via an increase in indexes of ATP (aquatic toxicity) and TTP (Terrestrial toxicity) when improperly managed. The presence of these pollutants in the waste stream from the FD process may explain the higher ATP $(0.0 .047 \mathrm{kPEI} / \mathrm{h})$ and TTP $(1.08 \mathrm{kPEI} / \mathrm{h})$ indexes of the FD process compared to the AP $(0.0085 \mathrm{kPEI} / \mathrm{h})$ and TTP $(0.278 \mathrm{kPEI} / \mathrm{h})$ values of the TFO process. The higher impact AP (acidification potential) index value $(0.213 \mathrm{kPEI} / \mathrm{h})$ for the FD process relative to the AP index value $(0.213 \mathrm{kPEI} / \mathrm{h})$ of the TFO process is due to need for external fossil energy to satisfy the heating energy needs of the FD process. This is because the use of these fuels will lead to the unwanted production of oxides such as $\mathrm{CO}_{2}$ that are capable of forming weak acids (i.e. $\mathrm{H}_{2} \mathrm{CO}_{3}$ for acid rain production. The study therefore suggests the preference for the TFO process compared to the FD process if only the environmental performance metric is considered. This observation contradicts the conclusions based on the economic performance metric since the FD process was shown to be preferable to the TFO process as illustrated by its lower MSP of AA. Such a scenario therefore presents a conundrum, with the selection of the preferred AA production pathway dependent on tradeoffs between the need for favorable economic and environmental outcomes by decision makers.

\section{Conclusion}

The study presents an initial comparative analysis of the two acrylic acid (AA) production pathways while employing waste apple pomace (WAP) as a renewable resource. In this study, we assessed FD and TFO processes as alternative approaches. The FD process incorporates an initial pretreatment operation for the production of a hydrolysate stream containing useful sugars followed by fermentation of these sugars for lactic acid (LA) production prior to LA dehydration for AA production. The TFO process on the other hand integrates the gasification of WAP followed by the fermentation of the syngas for alcohol production, which is employed as a precursor for propylene gas production, prior to a catalytic oxidation process for AA production. Considering both processes, although the designed processes are speculative, the FD process was shown to present an improved economic performance relative to the TFO process. This is highlighted by the lower MSP of the AA product from the FD process of US\$ 1.17 per $\mathrm{kg}$ relative to the MSP of US\$ 1.56 per $\mathrm{kg}$ from the AA product of the TFO process. Crucially, the TFO process presented an improved environmental performance compared to the FD process thus presenting a decision challenge for policy makers. The need for further multi-criteria decision assessment is therefore proposed.

List of abbreviations

\begin{tabular}{cc}
\hline Abbreviations & Full words \\
\hline FD & Fermentation-dehydration \\
TFO & Thermochemical-fermentation-oxidation \\
WAP & Waste apple pomace \\
AA & Acrylic acid \\
LA & Lactic acid \\
GHG & Greenhouse gas \\
NRTL & Non-random two-liquid \\
RSTOIC & Stoichiometric reactor model \\
RGIBBS & Equilibrium reactor model \\
RADFRAC & Rigorous distillation column model \\
CHP & Combined heat and power \\
HHV & higher heating value \\
TCI & total capital investment \\
TOC & total operating costs \\
FCI & Fixed capital investment \\
&
\end{tabular}




\begin{tabular}{cc}
\hline WCI & Working capital investment \\
TDC & Total direct cost \\
TIDC & Total indirect cost \\
APEA & ASPEN process economic analyzer \\
CEPCI & Chemical Engineering Plant Cost Index \\
\hline
\end{tabular}

Author Contributions: Conceptualization, O.V.O, methodology, O.V.O. and L.N, software, O.V.O.; validation, A.S. and H.A.., writing-original draft preparation, O.V.O., L.N., and A.S.; writing-review and editing O.V.O, H.A., and A.S.

Funding: This research received no external funding

Institutional Review Board Statement: Not applicable.

Informed Consent Statement: Not applicable

Acknowledgments: The first author gratefully acknowledges the financial support of Wallonia-Brussels International via the Wallonie-Bruxelles International (WBI) excellence Postdoctoral fellowship. Materne company is also acknowledged for their expert information input.

Conflicts of Interest: The authors declare no conflict of interest

\section{References}

1. Moriarty, P.; Honnery, D. The risk of catastrophic climate change: Future energy implications. Futures 2021, 128, 102728, doi:https://doi.org/10.1016/j.futures.2021.102728.

2. Okoro, O.V.; Sun, Z.; Birch, J. Meat processing waste as a potential feedstock for biochemicals and biofuels - A review of possible conversion technologies. Journal of Cleaner Production 2017, 142, 1583-1608, doi:https://doi.org/10.1016/j.jclepro.2016.11.141.

3. Mehmood, M.A.; Liu, C.-G.; Reungsang, A. Editorial: special issue "Sustainable biorefinery approaches". Biomass Conversion and Biorefinery 2021, doi:10.1007/s13399-021-01422-z.

4. Okoro, O.V.; Sun, Z.; Birch, J. 10 - Thermal depolymerization of biogas digestate as a viable digestate processing and resource recovery strategy. In Advances in Eco-Fuels for a Sustainable Environment, Azad, K., Ed.; Woodhead Publishing: 2019; pp. 277-308.

5. Yates, M.; Gomez, M.R.; Martin-Luengo, M.A.; Ibañez, V.Z.; Martinez Serrano, A.M. Multivalorization of apple pomace towards materials and chemicals. Waste to wealth. Journal of Cleaner Production 2017, 143, 847-853, doi:https://doi.org/10.1016/j.jclepro.2016.12.036.

6. Okoro, O.V.; Shavandi, A. An assessment of the utilization of waste apple slurry in bio-succinic acid and bioenergy production. International Journal of Environmental Science and Technology 2021, doi:10.1007/s13762-021-03235-z.

7. Hobbi, P.; Okoro, O.V.; Delporte, C.; Alimoradi, H.; Podstawczyk, D.; Nie, L.; Bernaerts, K.V.; Shavandi, A. Kinetic modelling of the solid-liquid extraction process of polyphenolic compounds from apple pomace: influence of solvent composition and temperature. Bioresources and Bioprocessing 2021, 8, 114, doi:10.1186/s40643-021-00465-4.

8. Landi, G.; Lisi, L.; Russo, G. Oxidation of propane and propylene to acrylic acid over vanadyl pyrophosphate. Journal of Molecular Catalysis A: Chemical 2005, 239, 172-179, doi:https://doi.org/10.1016/j.molcata.2005.06.018.

9. Mazloom, G.; Alavi, S.M. Kinetic study of selective propane oxidation to acrylic acid over Mo1V0.3Te0.23Nb0.12Ox using the genetic algorithm. Reaction Kinetics, Mechanisms and Catalysis 2013, 110, 387-403, doi:10.1007/s11144013-0607-9. 

Chemengonline: Available online: https://www.chemengonline.com/acrylic-acid-production-via-propylene-oxidationintratec-solutions/ [assessed on 30/4/2021], 2016.

11. Brown, D. Acrylic Acid. In Encyclopedia of Toxicology (Third Edition), Wexler, P., Ed.; Academic Press: Oxford, 2014; pp. 74-75.

12. Serrano-Aroca, A. Latest improvements of acrylic-based polymer properties for biomedical applications. $2017,1,13$.

13. Jin, X.; Meng, K.; Zhang, G.; Liu, M.; Song, Y.; Song, Z.; Yang, C. Interfacial catalysts for sustainable chemistry: advances on atom and energy efficient glycerol conversion to acrylic acid. Green Chemistry 2021, 23, 51-76, doi:10.1039/D0GC02913K.

14. Staples, T.L.; Chatterjee, P.K. Chapter VIII - Synthetic Superabsorbents. In Textile Science and Technology, Chatterjee, P.K., Gupta, B.S., Eds.; Elsevier: 2002; Volume 13, pp. 283-322.

15. Grand-View-Research. Acrylic Acid Market Size Worth \$22.55 Billion By 2022; Grand-View-Research: Dublin, Ireland, 2016.

16. Expertmarketresearch. Global Acrylic Acid Market: By Applications: Acrylate Esters, Super Absorbent Polymer (SAP), Others; Regional Analysis; Historical Market and Forecast (2016-2026); Market Dynamics; SWOT Analysis; Porter's Five Forces Analysis; Value Chain Analysis; Compet; Expertmarketresearch: Wyoming 2020.

17. Kim, M.; Lee, H. Highly Selective Production of Acrylic Acid from Glycerol via Two Steps Using Au/CeO2 Catalysts. ACS Sustainable Chemistry \& Engineering 2017, 5, 11371-11376, doi:10.1021/acssuschemeng.7b02457.

18. Danner, H.; Ürmös, M.; Gartner, M.; Braun, R. Biotechnological production of acrylic acid from biomass. Applied Biochemistry and Biotechnology 1998, 70, 887-894, doi:10.1007/BF02920199.

19. Straathof, A.J.J.; Sie, S.; Franco, T.T.; van der Wielen, L.A.M. Feasibility of acrylic acid production by fermentation. Applied Microbiology and Biotechnology 2005, 67, 727-734, doi:10.1007/s00253-005-1942-1.

20. Petrescu, L.; Fermeglia, M.; Cormos, C.-C. Life Cycle Analysis applied to acrylic acid production process with different fuels for steam generation. Journal of Cleaner Production 2016, 133, 294-303, doi:https://doi.org/10.1016/j.jclepro.2016.05.088.

21. Iglesias, J.; Martínez-Salazar, I.; Maireles-Torres, P.; Martin Alonso, D.; Mariscal, R.; López Granados, M. Advances in catalytic routes for the production of carboxylic acids from biomass: a step forward for sustainable polymers. Chemical Society Reviews 2020, 49, 5704-5771, doi:10.1039/D0CS00177E.

22. Yan, B.; Liu, Z.-H.; Liang, Y.; Xu, B.-Q. Acrylic Acid Production by Gas-Phase Dehydration of Lactic Acid over K+Exchanged ZSM-5: Reaction Variable Effects, Kinetics, and New Evidence for Cooperative Acid-Base Bifunctional Catalysis. Industrial \& Engineering Chemistry Research 2020, 59, 17417-17428, doi:10.1021/acs.iecr.0c02148.

23. Lyu, S.; Wang, T. Efficient production of acrylic acid by dehydration of lactic acid over BaSO4 with crystal defects. RSC Advances 2017, 7, 10278-10286, doi:10.1039/C6RA28429A.

24. Wojcieszak, R.; Bonnotte, T.; Paul, S.; Katryniok, B.; Dumeignil, F. Lactic Acid Conversion to Acrylic Acid Over Fluoride-Substituted Hydroxyapatites. 2020, 8, doi:10.3389/fchem.2020.00421.

25. de Resende, T.M.; da Costa, M.M. Chapter 12 - Biopolymers of sugarcane. In Sugarcane Biorefinery, Technology and Perspectives, Santos, F., Rabelo, S.C., De Matos, M., Eichler, P., Eds.; Academic Press: 2020; pp. 229-254.

26. Kehrer, M. Liquid-phase dehydration of lactic acid for the production of bio-acrylic acid Development of a multi-step process. Friedrich-Alexander-Universität Erlangen-Nürnberg (FAU), 2019.

27. Xu, X.; Lin, J.; Cen, P. Advances in the Research and Development of Acrylic Acid Production from Biomass1 1Supported by the Special Funds for Major State Basic Research Program of China (973 Program, No.2004CCA05500). Chinese Journal of Chemical Engineering 2006, 14, 419-427, doi:https://doi.org/10.1016/S1004-9541(06)60094-3. 
28. Pistikopoulos, E.N.; Stefanis, S.K.; Livingston, A.G.A. Methodology for Minimum Environmental Impact Analysis. Symp. Ser. 1995, 35, 4128.

29. Shonnard, D.R.; Hiew, D.S. Comparative Environmental assessments of VOC Recovery and recycle design alaternatives for gaseous waste streams. Environ. Sci. Technol. 2000, 34, 5222-5228.

30. Young, D.M.; Cabezas, H. Designing sustainable processes with simulation: the waste reduction (WAR) algorithm. Computers and Chemical Engineering 1999, 23, 1477-1491.

31. Gustafsson, J.; Landberg, M.; Bátori, V.; Åkesson, D.; Taherzadeh, M.J.; Zamani, A. Development of Bio-Based Films and 3D Objects from Apple Pomace. Polymers (Basel) 2019, 11, 289, doi:10.3390/polym11020289.

32. Zhang, B.; Heidari, M.; Regmi, B.; Salaudeen, S.; Arku, P.; Thimmannagari, M.; Dutta, A. Hydrothermal Carbonization of Fruit Wastes: A Promising Technique for Generating Hydrochar. 2018, 11, 2022.

33. Marcotullio, G. The chemistry and technology of furfural production in modern lignocellulose-feedstock biorefineries. 2011.

34. Peña-Tejedor, S.; Murga, R.; Sanz, M.T.; Beltrán, S.J.F.p.e. Vapor-liquid equilibria and excess volumes of the binary systems ethanol+ ethyl lactate, isopropanol+ isopropyl lactate and n-butanol+ n-butyl lactate at $101.325 \mathrm{kPa} .2005$, 230, 197-203.

35. Deterre, S.; Albet, J.; Joulia, X.; Baudouin, O.; Giampaoli, P.; Decloux, M.; Athes, V.J.J.o.C.; Data, E. Vapor-liquid equilibria measurements of bitter orange aroma compounds highly diluted in boiling hydro-alcoholic solutions at 101.3 kPa. 2012, 57, 3344-3356.

36. Vu, D.T.; Lira, C.T.; Asthana, N.S.; Kolah, A.K.; Miller, D.J.J.J.o.C.; Data, E. Vapor- liquid equilibria in the systems ethyl lactate+ ethanol and ethyl lactate+ water. 2006, 51, 1220-1225.

37. Cempa-Balewicz, M.; Jacek Łączny, M.; Smoliński, A.; Iwaszenko, S. Equilibrium Model of Steam Gasification of Coal. Journal of Sustainable Mining 2013, 12, 21-28, doi:https://doi.org/10.7424/jsm130203.

38. Sreejith, C.C.; Muraleedharan, C.; Arun, P. Thermo-Chemical Analysis of Biomass Gasification by Gibbs Free Energy Minimization Model-Part: II (Optimization of Biomass Feed and Steam to Biomass Ratio). International Journal of Green Energy 2013, 10, 610-639, doi:10.1080/15435075.2012.709203.

39. Basu, P. Biomass gasification and pyrolysis: practical design and theory; Academic press: 2010.

40. Okoro, O.V.; Sun, Z.; Birch, J. Techno-Economic Assessment of a Scaled-Up Meat Waste Biorefinery System: A Simulation Study. 2019, 12, 1030.

41. Petersen, A.M.; Chireshe, F.; Okoro, O.; Gorgens, J.; Van Dyk, J. Evaluating refinery configurations for deriving sustainable aviation fuel from ethanol or syncrude. Fuel Processing Technology 2021, 219, 106879, doi:https://doi.org/10.1016/j.fuproc.2021.106879.

42. ASPEN-plus. Aspen Plus User Guide; ASPEN technology incorporated: Cambridge, 2000.

43. Petersen, A.M.; Okoro, O.V.; Chireshe, F.; Moonsamy, T.; Görgens, J.F. Systematic cost evaluations of biological and thermochemical processes for ethanol production from biomass residues and industrial off-gases. Energy Conversion and Management 2021, 243, 114398, doi:https://doi.org/10.1016/j.enconman.2021.114398.

44. Okoro, O.V.; Nie, L.; Hobbi, P.; Shavandi, A. Valorization of Waste Apple Pomace for Production of Platform Biochemicals: A Multi-Objective Optimization Study. Waste and Biomass Valorization 2021, 12, 6887-6901, doi:10.1007/s12649-021-01487-x.

45. Alibaba. Mechanical Dewatering device Available online: https://www.alibaba.com/product-detail/DewateringDewatering-Machine-NORSEN-Vehicular-

Sludge_1600051333912.html?spm=a2700.galleryofferlist.normal_offer.d_title.5c49383dKmOCni\&s=p (accessed on February/18/2021). 
46. Zimmer, E. Optimal use of resources and energy during fruit juice extraction; Fruit Processing: Nlederwenlngen, 2017.

47. Kim, D. Physico-Chemical Conversion of Lignocellulose: Inhibitor Effects and Detoxification Strategies: A Mini Review. Molecules 2018, 23, doi:10.3390/molecules23020309.

48. Pérez, J.A.; Ballesteros, I.; Ballesteros, M.; Sáez, F.; Negro, M.J.; Manzanares, P. Optimizing Liquid Hot Water pretreatment conditions to enhance sugar recovery from wheat straw for fuel-ethanol production. Fuel 2008, 87, 36403647, doi:https://doi.org/10.1016/j.fuel.2008.06.009.

49. Hijosa-Valsero, M.; Paniagua-García, A.I.; Díez-Antolínez, R. Biobutanol production from apple pomace: the importance of pretreatment methods on the fermentability of lignocellulosic agro-food wastes. Applied microbiology and biotechnology 2017, 101, 8041-8052.

50. Iyer, P.V.; Thomas, S.; Lee, Y. High-yield fermentation of pentoses into lactic acid. In Proceedings of the Twenty-First Symposium on Biotechnology for Fuels and Chemicals, 2000; pp. 665-677.

51. Su, C.-Y.; Yu, C.-C.; Chien, I.L.; Ward, J.D. Control of Highly Interconnected Reactive Distillation Processes: Purification of Raw Lactic Acid by Esterification and Hydrolysis. Industrial \& Engineering Chemistry Research 2015, 54, 6932-6940, doi:10.1021/ie5039133.

52. Kamble, S.P.; Barve, P.P.; Joshi, J.B.; Rahman, I.; Kulkarni, B.D. Purification of Lactic Acid via Esterification of Lactic Acid Using a Packed Column, Followed by Hydrolysis of Methyl Lactate Using Three Continuously Stirred Tank Reactors (CSTRs) in Series: A Continuous Pilot Plant Study. Industrial \& Engineering Chemistry Research 2012, 51, 1506-1514, doi:10.1021/ie200642j.

53. Lee, H. Development of lactic and succinic acid biorefinery configurations for integration into a thermomechanical pulp mill. École Polytechnique de Montréal, 2015.

54. Ghantani, V.C.; Lomate, S.T.; Dongare, M.K.; Umbarkar, S.B. Catalytic dehydration of lactic acid to acrylic acid using calcium hydroxyapatite catalysts. Green Chemistry 2013, 15, 1211-1217, doi:10.1039/C3GC40144H.

55. Engineeringtoolbox. Fuel Gases Heating Values; Engineeringtoolbox: Available online: https://www.engineeringtoolbox.com/heating-values-fuel-gases-d 823.html [accessed 24/04/221], 2021.

56. Berg, L. DEHYDRATION OF ACRYLIC ACID BY EXTRACTIVE DISTILLATION. 5,154,800, 1992.

57. Song, D.; Yang, J.-H.; Lee, C.-J. Conceptual design of water separation process in glycerol-based acrylic acid production. Chemical Engineering Research and Design 2020, 156, 324-332, doi:https://doi.org/10.1016/j.cherd.2020.01.036.

58. Gagliano, A.; Nocera, F.; Bruno, M.; Cardillo, G. Development of an Equilibrium-based Model of Gasification of Biomass by Aspen Plus. Energy Procedia 2017, 111, 1010-1019, doi:https://doi.org/10.1016/j.egypro.2017.03.264.

59. Pardo-Planas, O.; Atiyeh, H.K.; Phillips, J.R.; Aichele, C.P.; Mohammad, S. Process simulation of ethanol production from biomass gasification and syngas fermentation. Bioresource Technology 2017, 245, 925-932, doi:https://doi.org/10.1016/j.biortech.2017.08.193.

60. Okoro, O.V.; Faloye, F.D. Comparative Assessment of Thermo-Syngas Fermentative and Liquefaction Technologies as Waste Plastics Repurposing Strategies. 2020, 2, 378-392.

61. Salaudeen, S.A.; Acharya, B.; Heidari, M.; Al-Salem, S.M.; Dutta, A. Hydrogen-Rich Gas Stream from Steam Gasification of Biomass: Eggshell as a CO2 Sorbent. Energy \& Fuels 2020, 34, 4828-4836, doi:10.1021/acs.energyfuels.9b03719.

62. Pala, L.P.R.; Wang, Q.; Kolb, G.; Hessel, V. Steam gasification of biomass with subsequent syngas adjustment using shift reaction for syngas production: An Aspen Plus model. Renewable Energy 2017, 101, 484-492, doi:https://doi.org/10.1016/j.renene.2016.08.069. 
63. Sreejith, C.C.; Muraleedharan, C.; Arun, P. Performance prediction of steam gasification of wood using an ASPEN PLUS thermodynamic equilibrium model. International Journal of Sustainable Energy 2014, 33, 416-434, doi:10.1080/14786451.2012.755977.

64. Doherty, W.; Reynolds, A.; Kennedy, D. Aspen plus simulation of biomass gasification in a steam blown dual fluidised bed. 2013.

65. Basu, P. Chapter 9 - Production of Synthetic Fuels and Chemicals from Biomass. In Biomass Gasification and Pyrolysis, Basu, P., Ed.; Academic Press: Boston, 2010; pp. 301-323.

66. Ukpong, M.N.; Atiyeh, H.K.; De Lorme, M.J.; Liu, K.; Zhu, X.; Tanner, R.S.; Wilkins, M.R.; Stevenson, B.S. Physiological response of Clostridium carboxidivorans during conversion of synthesis gas to solvents in a gas-fed bioreactor. Biotechnology and bioengineering 2012, 109, 2720-2728.

67. Tanner, R.S.; Miller, L.M.; Yang, D. Clostridium ljungdahlii sp. nov., an acetogenic species in clostridial rRNA homology group I. International Journal of Systematic and Evolutionary Microbiology 1993, 43, 232-236.

68. Phillips, J.R.; Klasson, K.T.; Clausen, E.C.; Gaddy, J.L. Biological production of ethanol from coal synthesis gas. Applied Biochemistry and Biotechnology 1993, 39, 559-571, doi:10.1007/BF02919018.

69. Petersen, A.M.; Okoro, O.V.; Du Preez, J.; Görgens, J.F. Evaluation of Biorefining Scenarios for Advanced Fuels Production from Triticale Grain. Energy \& Fuels 2020, 34, 11003-11013, doi:10.1021/acs.energyfuels.0c01568.

70. Arvidsson, M.; Lundin, B. Process integration study of a biorefinery producing ethylene from lignocellulosic feedstock for a chemical cluster (Msc Thesis) Chalmers University of Technology: Goteborg, 2011.

71. Calvar, N.; González, B.; Dominguez, A. Esterification of acetic acid with ethanol: Reaction kinetics and operation in a packed bed reactive distillation column. Chemical Engineering and Processing: Process Intensification 2007, 46, 1317-1323, doi:https://doi.org/10.1016/j.cep.2006.10.007.

72. Beucher, R.; Cammarano, C.; Rodríguez-Castellón, E.; Hulea, V. Direct conversion of ethylene to propylene over Niand W-based catalysts: An unprecedented behaviour. Catalysis Communications 2020, 144, 106091, doi:https://doi.org/10.1016/j.catcom.2020.106091.

73. Pérez Sánchez, A.; Pérez Sánchez, E.J.; Segura Silva, R.M. Simulation of the acrylic acid production process through catalytic oxidation of gaseous propylene using ChemCAD ${ }^{\circledR}$ simulator \%J Ingeniare. Revista chilena de ingeniería. $2019,27,142-150$.

74. Wibawanta, S.A.S. Catalytic partial oxidation of propylene for acrolein production. Curtin University, 2011.

75. $\quad$ Sinnot, R.; Towler, G. Chemical Engineering Design, 5th ed; Elsevier: Burlington, NJ, USA, 2009.

76. Devi, A.; Niazi, A.; Ramteke, M.; Upadhyayula, S. Techno-economic analysis of ethanol production from lignocellulosic biomass-a comparison of fermentation, thermo catalytic, and chemocatalytic technologies. Bioprocess and Biosystems Engineering 2021, doi:10.1007/s00449-020-02504-4.

77. Sinnot, R.; Towler, G. Chemical Engineering Design; Elsevier:: Burlington, NJ, USA, 2009.

78. Lamidi, R.O.; Wang, Y.; Pathare, P.B.; Roskilly, A.P.; Aguilar, M.C. Biogas Tri-generation for Postharvest Processing of Agricultural Products in a Rural Community: Techno-economic Perspectives. Energy Procedia 2017, 142, 63-69, doi:https://doi.org/10.1016/j.egypro.2017.12.011.

79. Granjo, J.; Duarte, B.; Oliveira, N. Soybean biorefinery: process simulation and analysis. J Chem. Eng. Trans 2015, 45, 583-588.

80. Dimitriou, I.; García-Gutiérrez, P.; Elder, R.H.; Cuéllar-Franca, R.M.; Azapagic, A.; Allen, R.W.K. Carbon dioxide utilisation for production of transport fuels: process and economic analysis. Energy \& Environmental Science 2015, 8, 1775-1789, doi:10.1039/C4EE04117H. 
81. Dutta, A.; Talmadge, M.; Hensley, J.; Worley, M.; Dudgeon, D.; Barton, D.; Groendijk, P.; Ferrari, D.; Stears, B.; Searcy, E.M. Process design and economics for conversion of lignocellulosic biomass to ethanol: thermochemical pathway by indirect gasification and mixed alcohol synthesis; National Renewable Energy Lab.(NREL), Golden, CO (United States): 2011.

82. Rickman, W.S. Handbook of Incineration of Hazardous Wastes (1991); CRC Press: 2017.

83. Towler, G.; Sinnott, R. Chemical engineering design: Principles, Practice and Economics of Plant and Process Design; Elsevier: Amsterdam, 2008.

84. Spath, P.; Aden, A.; Eggeman, T.; Ringer, M.; Wallace, B.; Jechura, J. Biomass to hydrogen production detailed design and economics utilizing the Battelle Columbus Laboratory indirectly-heated gasifier; National Renewable Energy Lab., Golden, CO (US): 2005.

85. DOE. Cost Estimating Guide Department of Energy https://www.directives.doe.gov/directives-documents/400series/0413.3-EGuide-21A/@@images/file, 2018.

86. Young, D.; Scharp, R.; Cabezas, H. The waste reduction (WAR) algorithm: environmental impacts, energy consumption, and engineering economics. Waste Management 200, 20, 605-615.

87. Okoro, O.V.; Sun, Z.; Birch, J. Catalyst-Free Biodiesel Production Methods: A Comparative Technical and Environmental Evaluation. Sustainability 2018, 10, 127.

88. Cabezas, H.; Bare, J.; Mallick, S. Pollution prevention with chemical process simulators: the generalized waste reduction (WAR) algorithm- full version. Comput. Chem. Eng 1999, 23, 623-634.

89. Young, D.M.; Cabezas, H. Designing sustainable processes with simulation: the waste reduction (WAR) algorithm. Computers \& chemical engineering 1999, 23, 1477-1491.

90. Gangadharan, P.; Kanchi, K.C.; Lou, H.H. Evaluation of the economic and environmental impact of combining dry reforming. Chemical Engineering Research and Design 2012, http://dx.doi.org/10.1016/j.cherd.2012.1004.1008.

91. Pubchem. Acrylic acid', National Library of Medicine: https://pubchem.ncbi.nlm.nih.gov/compound/Acrylic-acid, 2021.

92. WHO. ACRYLIC ACID HEALTH AND SAFETY GUIDE; IPCS INTERNATIONAL PROGRAMME ON CHEMICAL SAFETY Health and Safety Guide No. 104: GENEVA, 1997.

93. Culp, A.; Holmes, K.; Nagrath, R.; Nessenson, D. Propane to Acrylic Acid; School of Engineering and Applied Science University of Pennsylvania: Pennsylvania, 2013.

94. Salaudeen, S.A.; Acharya, B.; Dutta, A. Steam gasification of hydrochar derived from hydrothermal carbonization of fruit wastes. Renewable Energy 2021, 171, 582-591, doi:https://doi.org/10.1016/j.renene.2021.02.115.

95. Xia, W.; Takahashi, A.; Nakamura, I.; Shimada, H.; Fujitani, T. Study of active sites on the MFI zeolite catalysts for the transformation of ethanol into propylene. Journal of Molecular Catalysis A: Chemical 2010, 328, 114-118, doi:https://doi.org/10.1016/j.molcata.2010.06.008.

96. Gullón, B.; Garrote, G.; Alonso, J.L.; Parajó, J.C. Production of l-lactic Acid and Oligomeric Compounds from Apple Pomace by Simultaneous Saccharification and Fermentation: A Response Surface Methodology Assessment. Journal of Agricultural and Food Chemistry 2007, 55, 5580-5587, doi:10.1021/jf070442v.

97. Akhtar, J.; Amin, N.A.S. A review on process conditions for optimum bio-oil yield in hydrothermal liquefaction of biomass. Renewable and Sustainable Energy Reviews 2011, 15, 1615-1624, doi:https://doi.org/10.1016/j.rser.2010.11.054.

98. Midgett, J.S. Assessing a hydrothermal liquefaction process using biomass feedstocks. 2008.

99. Remón, J.; Randall, J.; Budarin, V.L.; Clark, J.H. Production of bio-fuels and chemicals by microwave-assisted, catalytic, hydrothermal liquefaction (MAC-HTL) of a mixture of pine and spruce biomass. Green Chemistry 2019, 21, 284-299. 
100. Demirbas, A. Higher heating values of lignin types from wood and non-wood lignocellulosic biomasses. Energy Sources, Part A: Recovery, Utilization, and Environmental Effects 2017, 39, 592-598, doi:10.1080/15567036.2016.1248798.

101. Okoro, O.V.; Sun, Z.; Birch, J. Meat processing dissolved air flotation sludge as a potential biodiesel feedstock in New Zealand: A predictive analysis of the biodiesel product properties. Journal of Cleaner Production 2017, 168, 1436-1447, doi:https://doi.org/10.1016/j.jclepro.2017.09.128.

102. Cheali, P.; Gernaey, K.V.; Sin, G. Uncertainties in Early-Stage Capital Cost Estimation of Process Design - A Case Study on Biorefinery Design. 2015, 3, doi:10.3389/fenrg.2015.00003. 